\title{
Accessibility of the urban environment for people with limited mobility using the example of Arkhangelsk
}

\author{
Olga Popova ${ }^{1 *}$, Alena Ostanina ${ }^{1}$, Svetlana Belyaeva ${ }^{2}$, and Yana Andryunina ${ }^{2}$ \\ ${ }^{1}$ Northern (Arctic) Federal University named after M.V. Lomonosov, Severnaya Dvina Emb. 17, \\ Arkhangelsk, 163002, Russia \\ ${ }^{2}$ Voronezh State Technical University, Moscow Avenue, 14, Voronezh, 394026, Russia
}

\begin{abstract}
The aim of the study is to assess the availability of urban space for people with limited mobility (PLM). Research objectives: - assessment of urban areas - determining the level of accessibility of the urban environment by assigning accessibility indices to certain territories (quarters); - testing using the example of separate quarters of the city of Arkhangelsk. Two non-adjacent city blocks located in its central part were selected for testing. According to the results of the study, it is possible to conclude that the availability of the urban environment for PLM in the selected quarters is: $37.2 \%$ for the first quarter, $42.1 \%$ for the second quarter. There is no comprehensive infrastructure suitable for PLM in the territory. Among the main problems are poor coating of footpaths, barriers in the form of curbs, the absence of railings on stairs, canopies and ramps, as well as the lack of equipped recreation places. A feature and advantage of the method is that the purpose of the study is not just a description of the quality characteristics of accessibility, but the determination of specific indicators of the security of various complex components of a comfortable urban environment. Integrated monitoring of the quality of the urban environment for PLM will allow the implementation of targeted programs and activities, taking into account their relevance to the expected effects. This contributes to the prudent use of financial resources. The totality of development programs and measures for individual territories will determine the development strategy of the city as a whole.
\end{abstract}

\section{Introduction}

Nowadays, the problems of organizing a comfortable urban environment are becoming one of the most important problems of territorial management of settlements and are being put forward as one of the most important large-scale state development programs in Russia.

A comfortable environment consists of many factors. The project of creating a comfortable urban environment includes the economic, commercial and budgetary effectiveness of the project, environmental impacts on the environment, the contribution of the project to improving the social environment and more [1].

${ }^{*}$ Corresponding author: oly-popova@yandex.ru 
Special attention is paid to the quality of social space. In particular, more and more multi-apartment residential complexes are well-kept, carefully organized, mostly green social spaces. However, as a rule, due to the limited number of services necessary for the proper functioning of the housing environment, they are closed [2].

When developing design estimates for land improvement, a number of factors must be taken into account, such as:

- location of the utility networks;

- geodesy of landscaped areas;

- the current legal situation with the ownership of land improvement objects and land plots;

- principles of accessibility for people with limited mobility;

- the need to move from a fragmented to a comprehensive principle of improvement of several adjacent yards at once;

- the professionalism of developers and the quality of project preparation [3].

A comfortable environment is the basis of a quality life, which is a strategic resource of the state. It includes indicators such as the maintenance of the city, the improvement of the yards, the creation and improvement of public territories. Based on this interpretation, the main elements of the urban environment are presented in three categories:

1) elements related to the territory and place of people residence (housing accommodations and housing and utility services) - a house and a yard;

2) elements that determine the movement of people from one point to another, ensuring and observing their safety during movement (pedestrian infrastructure and safety level) transit spaces;

3) elements characterizing those objects of the territory where people spend their time outside the home (the external attractiveness and uniqueness of the city; the well-being of public spaces; leisure, sports, entertainment) - points of attraction.

Studies show that the problem of creating a comfortable environment in Russia consists in a declining level of improvement of most of the territories of settlements against the background of a growing deficit of local budgets, systematic violations of existing norms and standards for maintaining courtyards and public spaces with growing needs of the population in a high-quality urban environment. Volumes of financing, even taking into account the co-financing of citizens, whose opinion is taken into account in the new approach to the formation of public spaces, make it possible to equip an extremely insignificant proportion of all urban areas.

The reason for this situation is also the spatial planning crisis. Responsibility for the current situation rests not only with the designers and investors of such complexes, but mainly with local authorities, whose goal should be to maintain spatial order in cities.

To solve the current problem, it is necessary to implement strategic urban planning programs in the context of improving the quality of the urban environment. The basis and tool for controlling the implementation of the program is monitoring the quality of the urban environment. In Russia, the assessment of the quality of the urban environment is carried out at the level of constituent entities and cities.

At the level of constituent entities of the Russian Federation, the priority project "Formation of a comfortable urban environment" is being implemented. The key objective of the project is to ensure the integrated development of modern urban infrastructure based on common approaches.

Within the framework of the project, a rating of constituent entities for its implementation was compiled - 81 regions (constituent entities of the Russian Federation that were not recipients of federal budget funds to support municipal programs for creating a comfortable urban environment were not assessed). Rating is made according to 28 indicators. The maximum possible number of points is 122 . The rating of individual 
constituent entities of the Russian Federation is shown in figure 1.

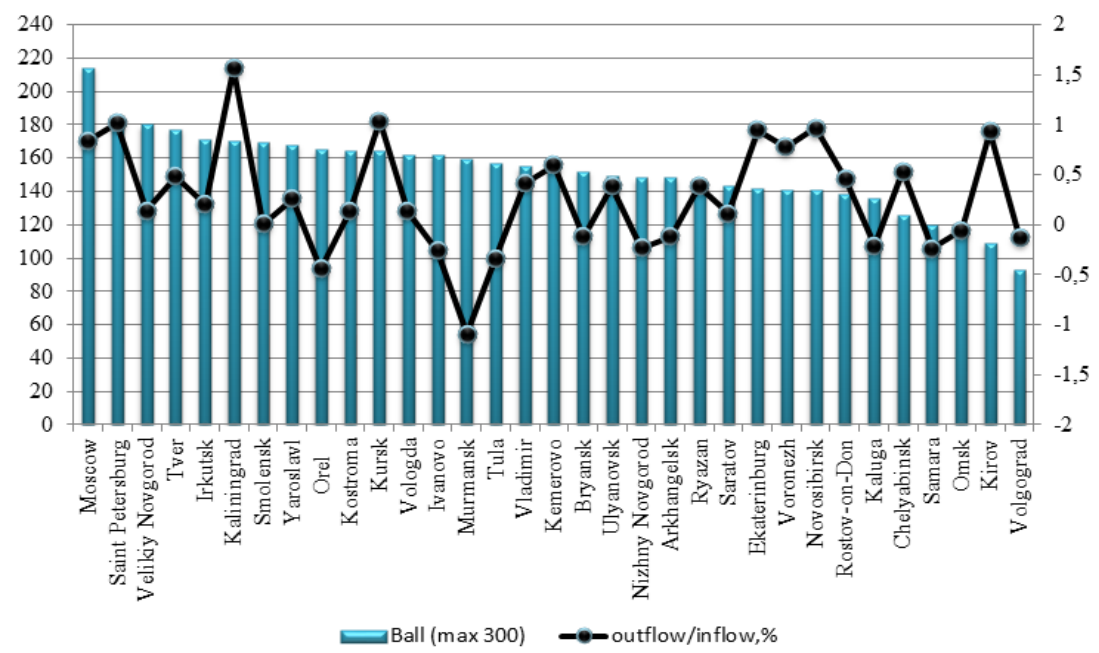

Fig. 1. Rating of individual constituent entities of the Russian Federation for the implementation of the program "Formation of a comfortable urban environment" for 2018

At the city level, the national project "Housing and urban environment" is being implemented. The project approved a methodology for determining the level of quality of the urban environment of settlements by calculating and assigning them an urban quality index. An assessment of the quality of the urban environment determines the current state of the urban environment, including identifying the advantages and disadvantages of cities, current problems. Nowadays, 1112 cities have been assessed.

Six types of spaces are assessed (housing and surrounding areas, landscaped and water spaces, street infrastructure, social and leisure infrastructure with surrounding areas, public and business infrastructure with surrounding areas, city-wide space) according to 5 criteria. In total, the assessment system consists of 30 indicators, each of which is responsible for a certain type of urban space and displays the degree of environmental quality according to one of the criteria.

The maximum number of points scored is 300. A score of less than 150 indicates a poor quality urban environment. The total points in relation to the outflow/inflow of population for individual cities of Russia are presented in figure 2.

According to the presented indicators, it can be concluded that the quality of the urban environment in most regions and cities is at a low level. This significantly affects the population, the development of the economy of the territories, the growth of social discontent.

Thus, improving the quality of life of the population in modern cities is the goal of smart planning. The improvement in quality is associated not only with issues of land use, urban design and density, but also to a large extent with mobility models. Urban mobility should be carried out in a comfortable and safe environment for all users, satisfying the expectations of people (especially vulnerable users) and the right to move [4].

A lot of studies have been done on the topic of organizing a comfortable urban environment. But studies related specifically to the problem of accessibility for people with limited mobility (hereinafter - PLM) are few. In particular, in the above methods for assessing the quality of the urban environment, an indicator that takes into account 
accessibility for PLM is mentioned only once in the framework of the project "Housing and urban environment" and is determined by the formula:

$$
m=\left(P_{\mathrm{s}} / P\right) \cdot 100 \%
$$

$m$ - the share of priority objects of social, transport, engineering infrastructure available for the disabled and other people with limited mobility in the total number of priority objects,

$P_{S}-$ the number of priority objects of social, transport, engineering infrastructure available for the disabled and other people with limited mobility,

$P$ - the total number of priority objects of social, transport, engineering infrastructure.

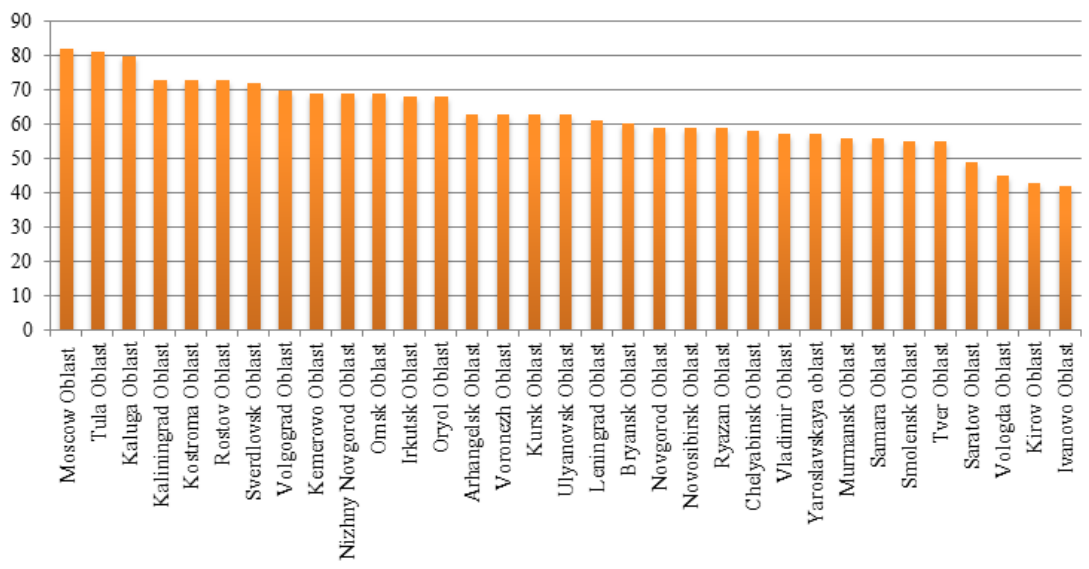

Fig. 2. The ratio of the urban environment quality index and the inflow/outflow of the population from 2015 to 2018

This indicator allows assessing the adaptability of the urban environment for unimpeded movement and obtaining the necessary services for people with limited mobility. However, each of the 6 types of spaces contains an accessibility indicator, which cannot be taken into account by this indicator alone.

Nowadays, the urgent issue is the organization of comfortable conditions for the person with low mobility in urban areas. These social categories are discriminated in urban societies. Modern cities, their infrastructure does not satisfy the needs of PLM. Their ability to move around and realize their potential in urban spaces is limited [5].

Components included in the composition of a comfortable urban environment should be adapted for PLM. Now in all developed countries, there is a desire to ensure the principle of creating equal opportunities for adaptation of the human environment and PLM. Nowadays, more and more activities of PLM are identified. Creating an accessible living environment is an integral part of the social policy of the state. It is necessary that PLM feel along with all residents of cities. An accessible environment plays a significant role in this. In case of compliance with its conditions and requirements, the population of the city or any other settlement can feel safe and use the urbanized space without barriers.

After analyzing current research in this area, it can be concluded that certain issues of mobility, individual components of a comfortable urban environment are considered. In particular: an analysis of the experience of introducing means to ensure accessibility for people with limited mobility in an already formed urban environment [6, 7], classification of the main population groups visiting transport hubs and their corresponding nodes and attraction foci $[8,9,10]$, provisions on landscape design of recreation zones for people with limited mobility [11] and others. There is no comprehensive solution to the problem of 
accessability for PLM. Separate scientific works are devoted to accessibility and mobility of urban environment, roads, space; spatial availability for urban facilities, as well as the definition of mixed use zones for the principle of a compact urban environment [12-17].

In Russia, the first regulatory documents on ensuring accessibility for PLM appeared in 1996. Nowadays, existing documents can be divided into 2 groups: regulatory documents regulating the requirements for the formation of an accessible environment and regulatory documents regulating requirements for means of ensuring a barrier-free environment. Table 1 and 2 show the time axis of development of 2 groups.

Table 1. Regulatory documents governing the requirements for creating an accessible environment

\begin{tabular}{|c|c|c|}
\hline \multirow[t]{2}{*}{ ลू } & SP 31-102-99 & $\begin{array}{l}\text { Accessibility requirements for public buildings and facilities for the } \\
\text { disabled and other people with limited mobility }\end{array}$ \\
\hline & SP $30-102-99$ & Planning and development of territories of low-rise housing construction \\
\hline \multirow[t]{4}{*}{ 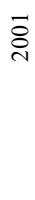 } & SP $35-101-2001$ & $\begin{array}{l}\text { Design of buildings and structures, taking into account accessibility for } \\
\text { people with limited mobility }\end{array}$ \\
\hline & SP $35-102-2001$ & $\begin{array}{l}\text { Living environment with planning elements accessible to people with } \\
\text { disabilities }\end{array}$ \\
\hline & SP 35-103-2001 & Public buildings and facilities accessible to visitors with limited mobility \\
\hline & SP $35-104-2001$ & Buildings and premises with places for disabled people \\
\hline \multirow{7}{*}{ 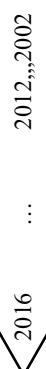 } & SP $35-105-2002$ & $\begin{array}{l}\text { Reconstruction of urban development, taking into account accessibility for } \\
\text { the disabled and other people with limited mobility }\end{array}$ \\
\hline & SP 140.13330 .2012 & City environment. Design rules for people with limited mobility \\
\hline & $\begin{array}{l}\text { Rev. No.1 to SP } \\
136.13330 .2012\end{array}$ & $\begin{array}{l}\text { Buildings and constructions. General design considerations for } \\
\text { accessibility for people with limited mobility }\end{array}$ \\
\hline & SP 136.13330 .2012 & $\begin{array}{l}\text { Buildings and constructions. General design considerations for } \\
\text { accessibility for people with limited mobility }\end{array}$ \\
\hline & $\begin{array}{l}\text { Rev. No.1 to SP } \\
59.13330 .2012\end{array}$ & Updated edition of SNiP 35-01-2001 \\
\hline & SP 59.13330 .2012 & Code of Accessibility of buildings and structures for PLM \\
\hline & SP 59.13330 .2016 & Code of Accessibility of buildings and structures for PLM \\
\hline
\end{tabular}

Table 2. Regulatory documents governing the requirements for means of ensuring a barrier-free environment

\begin{tabular}{|c|c|c|}
\hline ஜั & GOST R 50917-96 & Braille devices. General specifications \\
\hline \multirow{2}{*}{$\stackrel{m}{\stackrel{2}{c}}$} & $\begin{array}{l}\text { GOST R ISO 23600- } \\
2013\end{array}$ & $\begin{array}{l}\text { Auxiliary technical equipment for persons with visual impairment and } \\
\text { hearing impairment. Sound and tactile signals of traffic lights }\end{array}$ \\
\hline & GOST 55555-2013 & $\begin{array}{l}\text { Lifting platforms for the disabled and other people with limited mobility. } \\
\text { Security and availability requirements }\end{array}$ \\
\hline \multirow{4}{*}{$\begin{array}{l} \pm \\
\stackrel{\sim}{\circ} \\
\cdots \\
\stackrel{\sim}{\circ}\end{array}$} & $\begin{array}{l}\text { GOST R ISO 9999- } \\
2014\end{array}$ & Aids for people with disabilities. Classification and terminology \\
\hline & GOST R 56832-2015 & $\begin{array}{c}\text { The national standard of the Russian Federation for Braille. Requirements } \\
\text { and dimensions }\end{array}$ \\
\hline & GOST R 56421-2015 & $\begin{array}{c}\text { Lifting platforms for the disabled and other people with limited mobility. } \\
\text { General safety requirements for operation }\end{array}$ \\
\hline & GOST R 51671-2015 & $\begin{array}{l}\text { Communication facilities and technical information for general use } \\
\text { accessible to persons with disabilities. Classification. Availability and } \\
\text { security requirements }\end{array}$ \\
\hline \multirow[t]{3}{*}{$\stackrel{\bar{\nu}}{\bar{c}}$} & GOST R 51261-2017 & $\begin{array}{l}\text { Types and technical requirements of supporting stationary rehabilitation } \\
\text { devices }\end{array}$ \\
\hline & GOST R 52875-2018 & $\begin{array}{l}\text { Technical requirements for tactile signposts for the persons with visual } \\
\text { impairment }\end{array}$ \\
\hline & GOST R 52131-2019 & $\begin{array}{l}\text { Technical requirements for representation of information for the disabled } \\
\text { people }\end{array}$ \\
\hline
\end{tabular}


Nowadays, work continues on the formation of a comfortable urban environment and the introduction of measures to increase the level of the barrier-free environment.

The purpose of this study is to assess the availability of urban space for PLM.

To achieve this goal, the following tasks are set:

- assessment of urban areas - determining the level of accessibility of the urban environment by assigning accessibility indices to certain territories (quarters);

- testing using the example of separate quarters of the city of Arkhangelsk.

\section{Methods}

The methodology for assessing the accessibility of the urban environment for PLM takes into account, first of all, the requirements of the Russian Code of Rules SP 59.13330.2012 "Accessibility of buildings and structures for people with limited mobility", according to which "design solutions for facilities accessible for PLM should provide:

- accessibility of places of the targeted visit and barrier-free movement;

- safety of traffic routes (including evacuation ones), as well as places of residence, service and employment;

- timely receipt by PLM of complete and high-quality information that allows navigating in space, using equipment (including for self-service), receiving services, participating in the labor and educational process;

- convenience and comfort of the living environment".

Assessment of the accessibility of the urban environment is carried out according to 4 criteria (internal logistics, external logistics, housing, social and cultural facilities). The rating system consists of 11 indicators. The maximum number of points is 300 . The process of assessing the characteristics of territories by accessibility for PLM includes the following steps:

1. Selection of a territory to assess accessibility;

2. Assessment of the internal logistics of the territory - an assessment of the accessibility (reach capability, comfort and safety) of pedestrian movement within the boundaries of the selected territory;

3. Assessment of external logistics - an assessment of the accessibility of the study area relative to other areas of the urban space, comfort and safety of movement between adjacent territories, the reach capability of objects of mass visit, including by residents of other areas of the city.

4. Assessment of the accessibility of the housing stock of the territory for PLM

5. Assessment of the accessibility of social, cultural and domestic facilities for PLM.

\subsection{Selection of a territory}

In the framework of the methodology, urban space was divided into separate studied territories. The boundaries of territories are determined by the boundaries of quarters and / or the main transport corridors of the city. To assess the territories, its full-scale survey with photofixations is carried out.

\subsection{Internal logistics}

Internal logistics of a territory is assessed by the quality of pedestrian paths according to the following indicators:

- the quality of the coating of paths, sidewalks, ramps;

- equipping pedestrian paths with ramps; 
- availability of recreational facilities available for PLM.

The quality of the coating of paths, sidewalks, ramps. According to SP 59.13330.2016 5.1 .11 , the coating of pedestrian paths, sidewalks, ramps should be made of solid materials, smooth, not creating vibration when moving along it.

Calculation of the indicator of the quality of the footpath coating:

$$
a_{\mathrm{p}}=\Sigma(\mathrm{i}=1 ; n)\left(k \cdot S_{\mathrm{i}}\right) / S_{\mathrm{t}},
$$

where $a_{\mathrm{p}}$ - final estimate;

$k$ - rating (0 - lack of road, 1 - unsatisfactory, 2 - poor, 3 - satisfactory, 4 - good, 5 excellent (reference));

$S_{\mathrm{i}}$ - the length of the estimated area, m;

$S_{\mathrm{t}}$ - the total length of the sites, $\mathrm{m}$.

Equipping pedestrian paths with ramps. According to SP 59.13330.2016, paragraph 5.1.5, at the intersection of pedestrian and transport tracks with a height difference of more than $0.015 \mathrm{~m}$, pedestrian paths are equipped with ramps on both sides of the carriageway or with artificial bumps along the entire width of the carriageway. At the passage through the carriageway, curb ramps must be installed at least $1.5 \mathrm{~m}$ wide, which must not protrude onto the carriageway.

According to SP 59.13330.2016, paragraph 5.1.9, the height of the curbstones along the edges of pedestrian paths on a section along lawns and landscaped areas should be at least $0.05 \mathrm{~m}$.

The difference in elevation of the curbstones along the operated lawns and landscaped areas adjacent to the pedestrian paths should not exceed $0.025 \mathrm{~m}$.

Calculation of the indicator of equipment of pedestrian paths with ramps:

$$
a_{\text {curb }}=\Sigma(\mathrm{i}=1 ; n) N / N_{\mathrm{t}},
$$

where $N$ - the number of curb ramps that meet regulatory requirements;

$N_{\mathrm{t}}$ - the total number of ramps that should be at the descent / ascent on the sidewalk.

Availability of recreation facilities available for PLM. According to SP 59.13330.2016, paragraph 5.3.1, at the site of the facility, it is necessary to provide at least $100-150 \mathrm{~m}$ of recreational facilities available for PLM on the main routes of movement of people.

The calculation of the indicator of availability of recreational facilities is carried out according to the formula:

$$
a_{\text {r.f. }}=N_{\text {r.f. }} /\left(S_{\mathrm{t}} \cdot 150\right),
$$

$N_{\text {r.f. }}$ - the number of recreational facilities present in a given quarter;

$S_{\mathrm{t}}-$ the total length of the sites, $\mathrm{m}$.

\subsection{External logistics}

As part of the study of logistics external to the territory under consideration, the accessibility of interchange and public transport hubs, the provision of a network of public passenger transport and pedestrian traffic are considered.

Accessibility of interchange and public transport hubs. According to SP 140.13330.2012, paragraph 6.3.12, stops of all types of urban transport should provide the possibility of safe independent boarding of the visually impaired people, boarding and disembarking of the disabled using wheelchairs. At stops, there should be well-readable route information in large print and in contrasting color, sound and/or radio information should be provided for the visually impaired about the routes and time of the expected arrival of vehicles, about the route number approaching the vehicle stop. 
The calculation of the indicator of accessibility of transport and interchange and public transport hubs for PLM is carried out according to the formula:

$$
a_{\text {stop }}=N / N_{\mathrm{t}},
$$

where $N$ - number of equipped stops (with a landing pad, information about routes),

$N_{\text {об }}-$ the total number of stops.

Reach capability of transport and road network. According to SP 42.13330.2011 Urban planning. Planning and development of urban and rural settlements. Updated edition:

- the distance of pedestrian approaches to the nearest public passenger transport stop should be no more than $500 \mathrm{~m}$.

- the distance of the pedestrian approaches to the nearest stop of public passenger transport from the objects of mass visit should be no more than $250 \mathrm{~m}$.

The calculation of the indicator of accessibility of residential buildings, public facilities, social facilities relative to public transport stops is carried out according to the formula:

$$
a_{\text {rad }}=N_{\text {cov.rad. }} / N_{\mathrm{t}} \text {, }
$$

where $N_{\text {cov.rad. }}$ - number of buildings covered,

$N_{\mathrm{t}}$ - the total number of buildings.

Comfort and safety of pedestrian communications. According to SP 140.13330.2012 paragraph 5.3.3, pedestrian crossings through the streets adjacent to the territory of the enterprise should be regulated. Pedestrian traffic lights that regulate the crossing should be equipped with a countdown board with a device for voice and sound accompaniment of a green signal with an orientation signal. Before regulated pedestrian crossings, warning tactile-contrast indicators with longitudinal reefs should be installed, as well as road signs "blind pedestrians".

The calculation of the indicator of comfort and safety of ground pedestrian crossings through the streets is carried out according to the formula.

$$
a_{\text {cros }}=\Sigma(\mathrm{i}=1 ; n) P_{\mathrm{i}} / n,
$$

where $P_{\mathrm{i}}-$ crossing the road with an assessment,

$n$ - the number of crossings over the road.

\subsection{Housing stock}

Reach capability of entrance groups of residential buildings for PLM. According to SP 59.13330.2016, paragraph 6.1.2, in the accessible entrances to the building (structure), the difference between the marks of the sidewalk and the vestibule should be minimized. With a height difference, the entrance platforms, in addition to the stairs, must have a ramp. Their handrails must comply with the technical requirements for fixed stationary devices. If the width of the stairs at the main entrances to the building is $4.0 \mathrm{~m}$ or more, dividing bilateral handrails should be additionally provided.

The outer ramp should have a slope of no steeper than 1:20 (5\%). With a limited construction site or the presence of underground utilities, it is allowed designing a ramp with a slope no steeper than 1:12 (8\%) with a march length of not more than $6.0 \mathrm{~m}$ in front of the entrance.

The calculation of the indicator of accessibility of entrance groups of residential buildings for PLM is calculated by the formula:

$$
a_{\text {entr }}=\Sigma(\mathrm{i}=1 ; n)\left(N_{\text {entr }} \cdot N_{\mathrm{fl}} \cdot k\right) / \Sigma(\mathrm{i}=1 ; n)\left(N_{\mathrm{entr}} \cdot N_{\mathrm{fl}}\right),
$$


where $N_{\text {ent }}$ - the number of entrances in each residential building;

$N_{\mathrm{fl}}$ - the number of floors in each residential building;

$k$ - evaluation criterion ( 0 - no ramp, 1 - with a ramp).

Comfort and safety of entrance groups of residential buildings for PLM. According to SP 59.13330.2016, paragraph 6.1.4, the entrance area at the entrances accessible for PLM should have a canopy, a drainage system and, depending on local climatic conditions, heating the surface of the stairs and ramps.

Calculation of the indicator of comfort and safety of the entrance group is carried out according to the formula:

$$
a_{\text {can }}=N / N_{\mathrm{t}},
$$

where $N$ - the number of ramps equipped with a canopy,

$N_{\mathrm{t}}-$ the total number of ramps.

\subsection{Objects of social, cultural and household purposes}

Objects of social, cultural and household purposes are divided into 3 groups, the characteristics of which are presented in Table 3.

Table 3. Objects of social, cultural and household purposes

\begin{tabular}{|c|c|c|c|c|c|}
\hline Name & $\begin{array}{l}\text { Objects included in the } \\
\text { registry }\end{array}$ & $\begin{array}{l}\text { Frequency of } \\
\text { visits }\end{array}$ & $\begin{array}{l}\text { Loca- } \\
\text { tion }\end{array}$ & $\begin{array}{l}\text { Service } \\
\text { radius }\end{array}$ & $\begin{array}{l}\text { Object } \\
\text { utilization } \\
\text { ratio }\end{array}$ \\
\hline 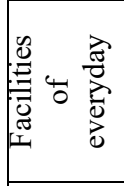 & $\begin{array}{c}\text { kindergartens, } \\
\text { nurseries, schools, } \\
\text { pharmacies, grocery } \\
\text { stores, banks, property } \\
\text { management } \\
\end{array}$ & every day & $\begin{array}{l}\text { in each } \\
\text { micro- } \\
\text { district }\end{array}$ & $\begin{array}{l}\text { no more than } \\
500 \mathrm{~m}\end{array}$ & $\begin{array}{c}1 /(5-20)= \\
0.2-0.05 \\
\text { (depending on } \\
\text { the location) }\end{array}$ \\
\hline 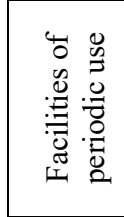 & $\begin{array}{l}\text { laundries, dry cleaners, } \\
\text { clinics, hairdressers, } \\
\text { sipermarkets, music, } \\
\text { art schools, libraries, } \\
\text { cinemas, sports } \\
\text { complexes, cafes }\end{array}$ & $\begin{array}{l}\text { Once a week } \\
\text { (taken } 4 \\
\text { quarters of the } \\
\text { city of } \\
\text { Arkhangelsk) }\end{array}$ & $\begin{array}{l}\text { in each } \\
\text { residenti } \\
\text { al area }\end{array}$ & $\begin{array}{l}\text { within } 2 \text { - } 3 \\
\text { stops from } \\
\text { home, no } \\
\text { more than } 15 \\
\text { minutes }\end{array}$ & $1 / 4=0.25$ \\
\hline 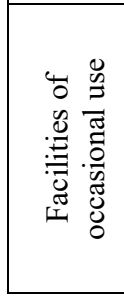 & $\begin{array}{c}\text { administrative and } \\
\text { business complexes, } \\
\text { museums, theaters, } \\
\text { exhibitions, concert } \\
\text { halls, galleries, large } \\
\text { supermarkets, } \\
\text { restaurants, parks, } \\
\text { specialized hospitals }\end{array}$ & $\begin{array}{l}1-2 \text { times a } \\
\text { month }\end{array}$ & $\begin{array}{l}\text { in the } \\
\text { city } \\
\text { center }\end{array}$ & $\begin{array}{c}30-50 \\
\text { minutes from } \\
\text { the } \\
\text { residential } \\
\text { area }\end{array}$ & 1 \\
\hline
\end{tabular}

The object utilization ratio shows how many people this object should be available to. The objects of the microdistrict value are assigned the lowest utilization ratio, the objects of citywide value are assigned the maximum utilization ratio. Each evaluated characteristic is multiplied by the utilization ratio.

Accessibility of entrance groups of social, cultural and household facilities for PLM. The calculation of the indicator of accessibility of entrance groups of facilities of social, cultural and household purposes is carried out according to the formula:

$$
a_{\text {ent.sch }}=\Sigma(\mathrm{i}=1 ; n)(k \cdot N \cdot m) / N_{\mathrm{t}},
$$


where $N$ - the number of social, cultural and household facilities equipped with entrance groups corresponding to regulatory requirements,

$N_{\mathrm{t}}$ - the total number of social, cultural and household facilities,

$k$ - criterion for accessibility of entrance groups (0 - no ramp, 1 - with a ramp + handrails),

$m$ - the utilization ratio of the object.

The presence of vertical transport systems in the objects of social, cultural and household purposes. The calculation of the indicator of the presence of vertical transport systems in the objects of social, cultural and household purposes is carried out according to the formula:

$$
a_{\mathrm{v} . \mathrm{t}}=\Sigma(\mathrm{i}=1 ; n) N / N_{\mathrm{t}}
$$

where $N$ - the number of social, cultural and household facilities equipped with vertical transport systems,

$N_{\mathrm{t}}$ - the total number of objects of social, cultural and household purposes.

Comfort and safety of entrance groups of social, cultural and household facilities for PLM. The calculation of the canopy indicator over the input group of social, cultural and domestic facilities is carried out according to formula 8 with multiplication by the correction factor presented in table 3 .

\section{Results and discussion}

Testing of the proposed methodology was carried out using the example of the territories of the city of Arkhangelsk. As the analysis showed, as of 2018, the Arkhangelsk region and the city of Arkhangelsk have low indicators of the level of development of the urban environment (fig. 1 and fig. 2):

- 62 points out of 122 possible according to the rating of the constituent entities of the Russian Federation for the implementation of the program "Formation of a comfortable urban environment";

- 148 points out of 300 possible according to the urban environment quality index in accordance with the methodology developed in the framework of the national project "Housing and urban environment" (below 150 points is considered poor quality of the urban environment).

As pilot territories, 2 non-adjacent city blocks located in its central part were selected (fig. 3). There are residential and socio-cultural-household facilities for both citywide and intra-quarter use in both quarters. 


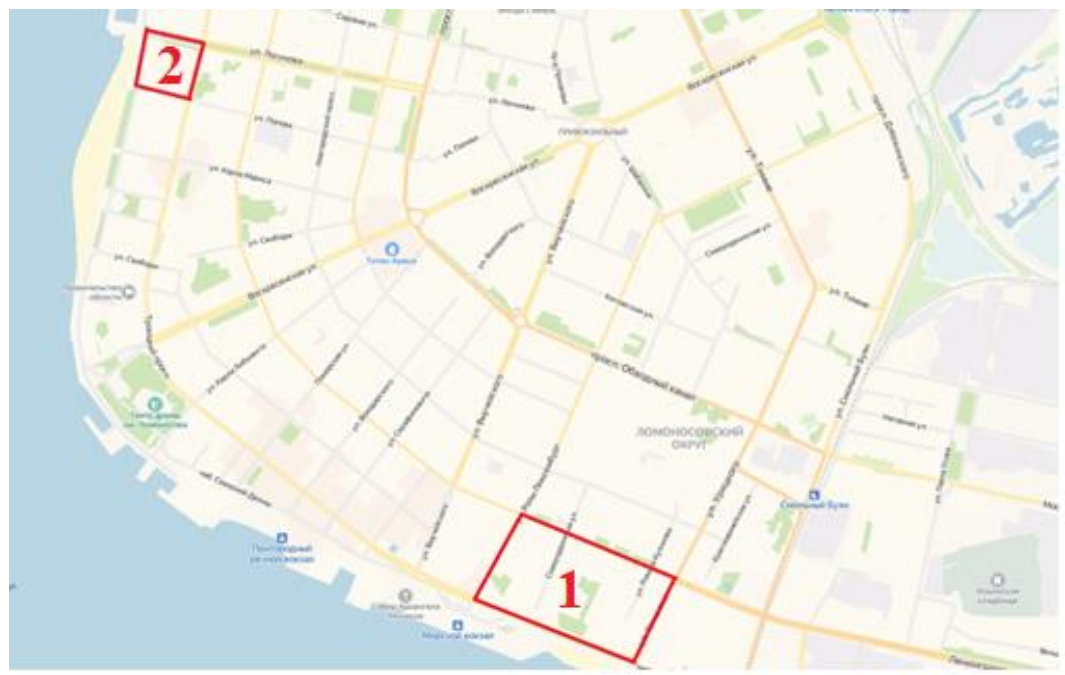

Fig. 3. Map of the territories under the study

The results of the survey and assessment of the accessibility of the urban environment for PLM are given in table 4.

Table 4. The results of the survey and assessment of the accessibility of the urban environment for PLM

\begin{tabular}{|c|c|c|}
\hline Name & \multicolumn{2}{|c|}{ Description and calculation } \\
\hline 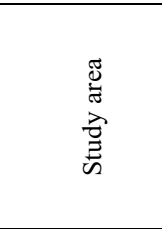 & $\begin{array}{l}\text { A quarter with cadastral number } 29: 22: \\
050515 \text {. In the quarter, there are mainly } \\
\text { wooden housing construction, many } \\
\text { educational institutions, as well as the main } \\
\text { educational buildings of Northern (Arctic) } \\
\text { Federal University named after M.V. } \\
\text { Lomonosov. }\end{array}$ & $\begin{array}{l}\text { A quarter with cadastral number } 29: 22: \\
040732 \text {. There are many social infrastructure } \\
\text { facilities in the quarter, including a city clinic. }\end{array}$ \\
\hline Criterion 1 & \multicolumn{2}{|c|}{ Internal logistics } \\
\hline Indicator 1.1 & \multicolumn{2}{|c|}{ The quality of the coating of paths, sidewalks, ramps } \\
\hline 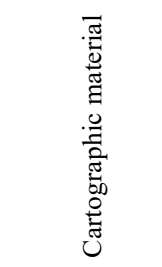 & $\div$ & 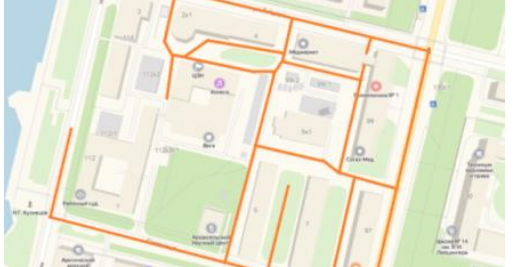 \\
\hline Calculation & $\begin{array}{c}k=0-S_{\mathrm{i}}=352 \mathrm{~m} \\
k=1-S_{\mathrm{i}}=691 \mathrm{~m} \\
k=2-S_{\mathrm{i}}=874 \mathrm{~m} \\
k=3-S_{\mathrm{i}}=691 \mathrm{~m} \\
k=4-S_{\mathrm{i}}=1986 \mathrm{~m} \\
k=5-S_{\mathrm{i}}=280 \mathrm{~m} \\
S_{\mathrm{t}}=4874 \mathrm{~m}\end{array}$ & $\begin{array}{c}k=0-S_{\mathrm{i}}=73 \mathrm{~m} \\
k=1-S_{\mathrm{i}}=117 \mathrm{~m} \\
k=2-S_{\mathrm{i}}=109 \mathrm{~m} \\
k=3-S_{\mathrm{i}}=157 \mathrm{~m} \\
k=4-S_{\mathrm{i}}=383 \mathrm{~m} \\
k=5-S_{\mathrm{i}}=224 \mathrm{~m} \\
S_{\mathrm{t}}=1063 \mathrm{~m}\end{array}$ \\
\hline Total $\mathrm{I}_{11}$ & 2.84 & 3.25 \\
\hline Indicator 1.2 & \multicolumn{2}{|c|}{ Equipping walking paths with ramps } \\
\hline Calculation & $\begin{array}{l}N=32 \\
N_{\mathrm{t}}=50\end{array}$ & $\begin{array}{l}N=12 \\
N_{\mathrm{t}}=30\end{array}$ \\
\hline Total $\mathrm{I}_{12}$ & 0.64 & 0.4 \\
\hline Indicator 1.3 & \multicolumn{2}{|c|}{ Availability of recreational facilities available for PLM } \\
\hline
\end{tabular}




\begin{tabular}{|c|c|c|}
\hline Calculation & $\begin{array}{l}S_{\mathrm{t}} / 150=32 \\
\quad N_{\text {r.f. }}=16\end{array}$ & $\begin{array}{l}S_{\mathrm{t}} / 150=7 \\
N_{\mathrm{r.f}}=4\end{array}$ \\
\hline Total $\mathrm{I}_{13}$ & 0.5 & 0.57 \\
\hline Criterion 2 & \multicolumn{2}{|c|}{ External logistics } \\
\hline Indicator 2.1 & \multicolumn{2}{|c|}{ Accessibility of interchange and public transport hubs } \\
\hline Calculation & $\begin{array}{l}N=0 \\
N_{\mathrm{t}}=4\end{array}$ & $\begin{array}{l}N=0 \\
N_{\mathrm{t}}=1\end{array}$ \\
\hline Total $\mathrm{I}_{21}$ & \multirow{2}{*}{\multicolumn{2}{|c|}{\begin{tabular}{l|l}
0 & \\
Reach capability of transport and road network
\end{tabular}}} \\
\hline Indicator 2.2 & & \\
\hline \multicolumn{3}{|l|}{ 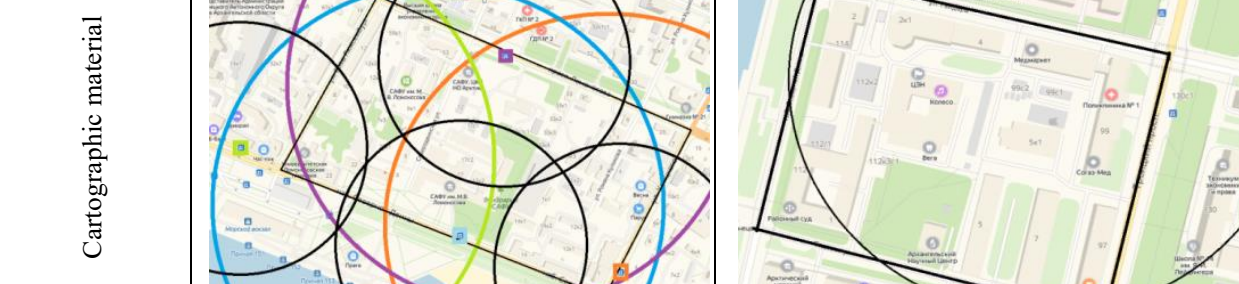 } \\
\hline Calculation & $\begin{array}{l}N=55 \\
N_{\mathrm{t}}=55\end{array}$ & $\begin{array}{l}N=10 \\
N_{\mathrm{t}}=10\end{array}$ \\
\hline Total $\mathrm{I}_{22}$ & 1 & 1 \\
\hline Indicator 2.3 & \multicolumn{2}{|c|}{ Comfort and safety of pedestrian communications } \\
\hline Calculation & $\begin{array}{c}P_{\mathrm{i}}=3 * 0.25=0.75 \\
n=4\end{array}$ & $\begin{array}{c}P_{\mathrm{i}}=0.25 \\
n=1\end{array}$ \\
\hline Total $\mathrm{I}_{23}$ & 0.19 & 0.25 \\
\hline Criterion 3 & \multicolumn{2}{|c|}{ Housing stock } \\
\hline Indicator 3.1 & \multicolumn{2}{|c|}{ Reach capability of entrance groups of residential buildings for PLM } \\
\hline Calculation & $\begin{array}{l}\text { Lomonosov Avenue, } 53 \\
\qquad \begin{array}{c}N_{\text {entr }}=2 \\
N_{\mathrm{fl}}=14 \\
k=1\end{array}\end{array}$ & $k=0$ \\
\hline Total $\mathrm{I}_{31}$ & 0.11 & 0 \\
\hline Indicator 3.2 & \multicolumn{2}{|c|}{ Comfort and safety of entrance groups of residential buildings for PLM } \\
\hline Calculation & $\begin{array}{l}N=0 \\
N_{\mathrm{t}}=1\end{array}$ & $\begin{array}{r}N=0 \\
N_{\mathrm{t}}=0 \\
\end{array}$ \\
\hline Total $\mathrm{I}_{32}$ & 0 & 0 \\
\hline Criterion 4 & \multicolumn{2}{|c|}{ Objects of social, cultural and household purposes } \\
\hline Indicator 4.1 & \multicolumn{2}{|c|}{ Accessibility of entrance groups of social, cultural and household facilities for PLM } \\
\hline Calculation & $\begin{array}{c}\text { Strekoza kindergarten: } k=1, m=0.1 \\
\text { Parus Shopping center: } k=1, m=0.1 \\
\text { Pyaterochka: } k=1, m=0.05 \\
N_{\mathrm{t}}=7\end{array}$ & $\begin{array}{l}\text { The first city clinic } k=1, m=0.25 \\
\text { Federal Service for State Registration, } \\
\text { Cadastre and Cartography } k=1, m=1 \\
\text { Employment center } k=1, m=0.25 \\
\qquad N_{\mathrm{t}}=3\end{array}$ \\
\hline Total $\mathrm{I}_{41}$ & 0.03 & 0.3 \\
\hline Indicator 4.2 & \multicolumn{2}{|c|}{$\begin{array}{l}\text { The presence of vertical transport systems in the objects of social, cultural and household } \\
\text { purposes }\end{array}$} \\
\hline Calculation & $\begin{array}{l}N=1 \\
N_{\mathrm{t}}=4\end{array}$ & $\begin{array}{l}N=2 \\
N_{\mathrm{t}}=4\end{array}$ \\
\hline Total $\mathrm{I}_{42}$ & 0.25 & 0.5 \\
\hline Indicator 4.3 & \multicolumn{2}{|c|}{ Comfort and safety of entrance groups of social, cultural and household facilities for PLM } \\
\hline Calculation & $\begin{array}{c}N=3 \\
N_{\mathrm{t}}=7 \\
m_{1}=0.1 ; m_{2}=0.1 ; m_{3}=0.05\end{array}$ & $\begin{array}{c}N=2 \\
N_{\mathrm{t}}=5 \\
m_{1}=0.25 ; m_{1}=0.25\end{array}$ \\
\hline Total $\mathrm{I}_{43}$ & 0.1 & 0.042 \\
\hline TOTAL & 5.66 & 6.31 \\
\hline
\end{tabular}


According to the results of the study, it is possible to conclude that the accessibility of the urban environment for PLM of pilot quarters is: $37.2 \%$ for the first quarter, $42.1 \%$ for the second quarter. The territory lacks a comprehensive infrastructure suitable for PLM.

The main factors that violate the accessible environment for PLM:

- engineering and technological ones: barriers on a linear path (pavement potholes, curb ramps), entry group barriers (lack of ramps, railings and canopies),

- social ones: lack of places of short rest, tactile and informational equipment (Braille, sound beacon, call button, time board, curb ramp, tactile tile).

Thus, the proposed methodology, unlike the existing ones [1-5], allows a comprehensive analysis of the territory within the boundaries of the studied territories, and assessment of the quality of the urban environment for PLM within the boundaries of the entire municipality by the totality of the characteristics of individual territories.

\section{Conclusion}

The methodology of a comprehensive assessment of the urban environment is a tool for identifying the most problematic nodes in ensuring a barrier-free space, allows identifying the areas that are most in need of updating and creating a comfortable urban environment. Its peculiarity and advantage also lie in the fact that the purpose of the study is not just a description of the quality characteristics of accessibility, but rather specific indicators of the security of various complex components of a comfortable urban environment.

The results of testing the methodology using the example of the territories of the city of Arkhangelsk revealed the main problems, among which poor-quality coating of footpaths, barriers in the form of a curbstone, the absence of railings on stairs, canopies and ramps, as well as the lack of equipped recreation areas, make it difficult to reach the territory. All together represents a dangerous, inaccessible and uncomfortable environment, which is not convenient not only for PLM and disabled people, but also for any resident of the city.

Strategic planning for the development of territories on the basis of a comprehensive monitoring of the quality of the urban environment allows the implementation of targeted programs and activities, taking into account the level of their social and economic efficiency. The development of measures, taking into account their relevance to the expected effects, contributes to the prudent use of financial resources and is a catalyst for improving the quality of the urban environment. The combination of development programs and activities for individual quarters determines the development strategy of the city as a whole.

\section{References}

1. E. Stein, International science conference SPBWOSCE-2016 - Smart city, 106 (2016) doi: 10.1051/matecconf/201710601036

2. M. Gyurkovich, A. Sotoca, 3rd World multidisciplinary civil engineering, architecture, urban planning symposium, 471 (2018) doi: 10.1088/1757-899X/471/9/092009

3. O. Petrina, M. Stadolin, Vestnik Universiteta, 6, 34-38 (2018) doi: 10.26425/18164277-2018-6-34-38

4. M. Tira, M. Tiboni, S. Rossetti, M. De Robertis, Smart planning: sustainability and mobility in the age of change, 201-213 (2018) doi: 10.1007/978-3-319-77682-8_12

5. L. Vlasenko, International science conference SPBWOSCE-2016 - Smart city, 106 (2017) doi: 10.1051/matecconf/201710601009

6. I. Kirichkov, Urban Studies, 2, 71-81 (2019) doi : 10.7256/2310-8673.2019.2.29735 
7. L. Talipova, E. Kosyakov, M. Romanovich, M. Lunyakov, MATEC Web Conf., 170 (2018) https://doi.org/10.1051/matecconf/201817002011

8. N. Danilina, S. Privezentseva, Vestnik of TSUAB (Journal of Construction and Architecture), 20, 49-56 (2018) doi: 10.31675/1607-1859-2018-20-3-49-56

9. E.D. Kosyakov 1, L.V. Talipova, M.A. Romanovich, A.I. Roshkovanova, T.L. Simankina, N.V. Braila, Construction of Unique Buildings and Structures, 70(7), 31-42 (2018) doi: 10.18720/CUBS.70.3

10. M. Romanovich, T. Simankina, Procedia Engineering, 165, 1587-1594 (2016) https://doi.org/10.1016/j.proeng.2016.11.897

11. N. Ivanova, N. Antonova, Architecture, 5, 112-114 (2016) https://doi.org/10.18454/IRJ.2016.47.093

12. C.P. Ng, T.H. Law, F.M. Jakarni, S. Kulanthayan, Transportation Research Part A: Policy and Practice, 117, 292-301 (2018) https://doi.org/10.1016/j.tra.2018.08.0321

13. J. Gonçalves, M. Gomes, S. Ezequiel, Case Studies on Transport Policy, 5, 643-655 (2017) https://doi.org/10.1016/j.cstp.2017.07.009

14. D.K. Tsiotas, O.S. Kalantzi, I.D. Gavardinas, Transportation Research Procedia, 24, 499-506 (2017) https://doi.org/10.1016/j.trpro.2017.05.089

15. D.A. Lessa, C. Lobo, L. Cardoso, Journal of Transport Geography, 77, 1-10 (2019) https://doi.org/10.1016/j.jtrangeo.2019.04.004

16. A.V.Vorontsova, V.L.Vorontsova, D.V.Salimgareev, Procedia Engineering, 150, 1996-2000 (2016) https://doi.org/10.1016/j.proeng.2016.07.277

17. F.R. Ashik, S.A. Mim, M.N. Neema, Journal of Urban Management, 9(1), 77-92 (2019) https://doi.org/10.1016/j.jum.2019.11.004 